\title{
Cytokine Secretion of Peripheral Blood Mononuclear Cells by Hydnocarpus anthelminthicus Seeds
}

\author{
Surang Leelawat $\mathbb{D}^{1}$ and Kawin Leelawat ${ }^{2}$ \\ ${ }^{1}$ Faculty of Pharmacy, Rangsit University, Amphoe Mueang, Pathum Thani 12000, Thailand \\ ${ }^{2}$ Department of Surgery, Rajavithi Hospital, Bangkok 10400, Thailand \\ Correspondence should be addressed to Surang Leelawat; surang.l@rsu.ac.th
}

Received 6 January 2018; Revised 28 April 2018; Accepted 6 May 2018; Published 3 June 2018

Academic Editor: Marcel Tanner

Copyright ( 2018 Surang Leelawat and Kawin Leelawat. This is an open access article distributed under the Creative Commons Attribution License, which permits unrestricted use, distribution, and reproduction in any medium, provided the original work is properly cited.

\begin{abstract}
Background. Hydnocarpus anthelminthicus is primarily used as a traditional medicine for the treatment of leprosy. Previous studies demonstrated that the clinical course of leprosy and the susceptibility to mycobacteria are recognized by the immune response of the host. The current study aims to investigate the effect of $H$. anthelminthicus seed oil and extracts on the secretion of cytokines from PBMCs involved in immune regulation. Methods. PBMCs from healthy volunteers were cultured and treated with LPS and H. anthelminthicus seed oil or extracts. Cell viability was detected with WST-1 cell proliferation assay reagent. Proinflammatory cytokines were quantified using ELISA with a specific antibody. Results. LPS-treated PBMCs significantly increased IL6 and TNF- $\alpha$ secretion. $H$. anthelminthicus seed oil had a synergistic effect with LPS on TNF- $\alpha$ secretion. The aqueous extract of $H$. anthelminthicus seed kernels and hulls significantly induced IL6 and TNF- $\alpha$ secretion. However, the ethanol extract of $H$. anthelminthicus seed kernels and hulls significantly decreased IL6, IL8, and TNF- $\alpha$ secretion in LPS-treated PBMCs. Conclusions. Extracts of $H$. anthelminthicus seeds demonstrated various effects on the proinflammatory cytokine secretion of PBMCs. The application of these extracts should depend on the immune response of the host, which determines the manifestation of the disease.
\end{abstract}

\section{Introduction}

Hydnocarpus anthelminthicus Pierre ex Laness. is a native Southeast Asian tree belonging to Flacourtiaceae. Hydnocarpus oil or chaulmoogra oil is prepared from the seeds of Hydnocarpus spp. and is primarily used as a traditional medicine for the treatment of leprosy [1].

Leprosy is a chronic disease caused by infection with Mycobacterium leprae. After infection, the immune response of the host determines the manifestation of the disease. Leprosy causes a peripheral neuropathy with potentially long-term disabilities [2, 3]. Its clinical spectrum ranges from tuberculoid leprosy through borderline forms to lepromatous leprosy of the Ridley-Jopling classification [4]. Tuberculoid leprosy is found in patients who have a strong cell-mediated immune response to $M$. leprae, limiting the disease to a few well-defined skin lesions [5]. Lepromatous leprosy is the severe form of leprosy presented with multiple skin involvements, neuropathy, blindness, and permanent disability. Patients with lepromatous leprosy have a poor cellular immune response but have high titers of ineffective antibodies against $M$. leprae [6].

However, there is no study of the effects of $H$. anthelminthicus on the immune response. In this study, the secretion of cytokines that are associated with immune responses for many systemic complications of infections, including IL6, IL8, IL10, and TNF- $\alpha$, is measured from peripheral blood mononuclear cells (PBMCs) treated with H. anthelminthicus.

A recent study demonstrated that TNF- $\alpha$ induces the immune response toward the elimination of the pathogen and/or mediates the pathologic manifestations of the disease. TNF- $\alpha$ was induced following stimulation of PBMCs with total or components of $M$. leprae, namely, lipoarabinomannan [7]. A previous study found that lipoarabinomannan enhances LPS-induced TNF- $\alpha$ production by engaging scavenger receptors of PBMCs [8].

To stimulate the secretion of TNF- $\alpha$ and other proinflammatory cytokines, PBMCs were treated with LPS. In addition, 


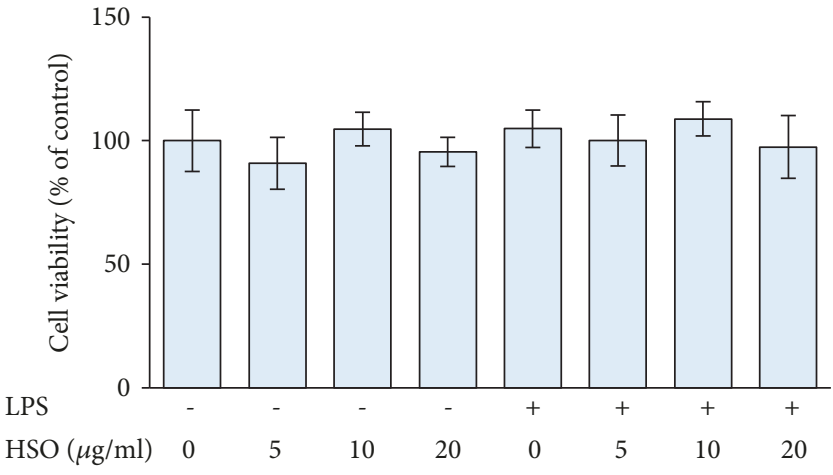

(a)

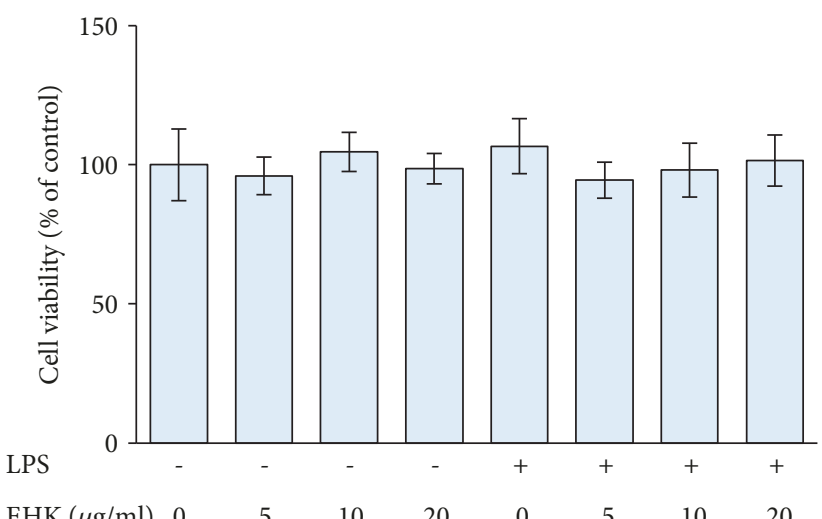

(c)

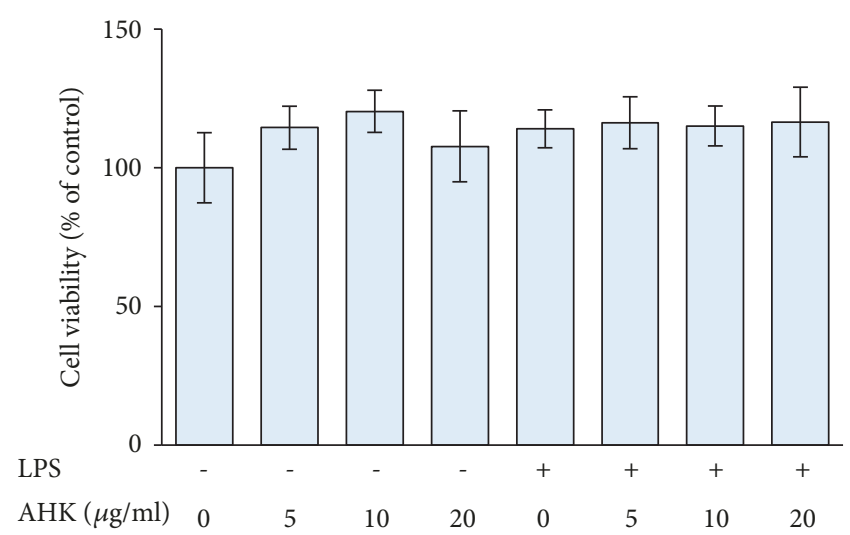

(b)

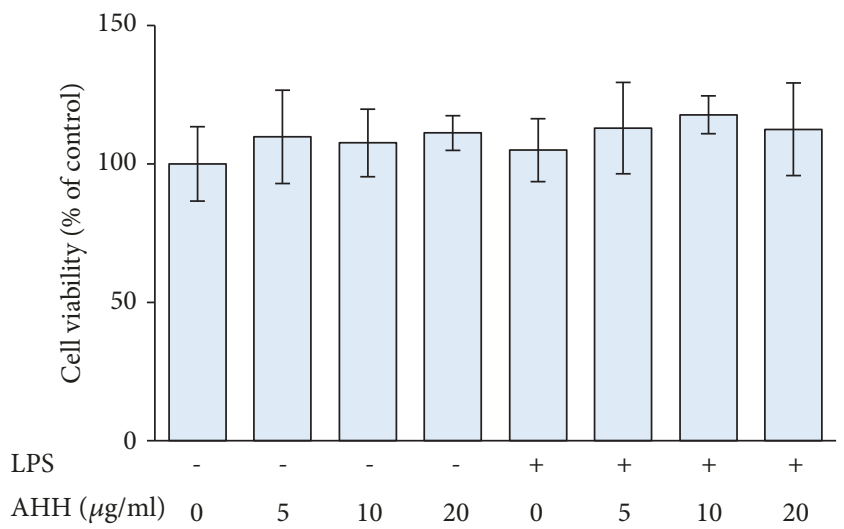

(d)

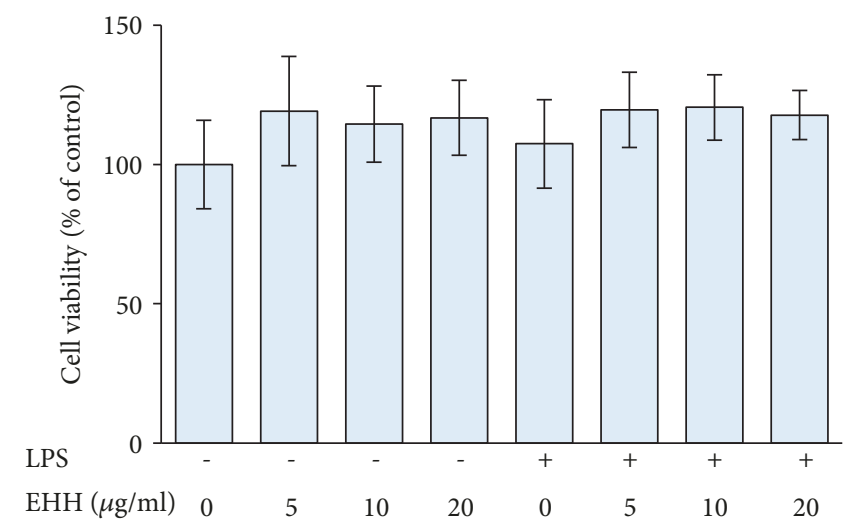

(e)

Figure 1: The effect of HSO (a), AHK (b), EHK (c), AHH (d), and EHH (e) on PBMC proliferation. PBMCs were separated using Ficoll-Paque density centrifugation, seeded in 96-well plates and treated with $10 \mu \mathrm{g} / \mathrm{ml} \mathrm{LPS}$ and extracts at the indicated concentrations. The cells were then incubated for $24 \mathrm{~h}$ before the addition of WST-1 cell proliferation assay reagent.

the modulation effect of $H$. anthelminthicus on cytokine secretion in LPS-treated PBMCs was examined.

\section{Materials And Methods}

2.1. Sample Preparation. Hydnocarpus anthelminthicus from Lampang province, Thailand, was cleaned, dried, and then separated into seed hulls and kernels. Seed kernels were cleaned, dried at $50^{\circ} \mathrm{C}$ for $30 \mathrm{~min}$, ground into paste, and pressed using a hydraulic presser. Seed kernel marc was then dried at $50^{\circ} \mathrm{C}$ for $30 \mathrm{~min}$, ground into paste, and extracted with $80 \%$ ethanol. Marc from the ethanol extract was then extracted with water by heating in a water bath for $30 \mathrm{~min}$, filtered, and evaporated using a freeze dryer. $H$. anthelminthicus seed oil (HSO), ethanol extract of $H$. anthelminthicus seed kernels (EHK), and aqueous extract of $H$. anthelminthicus seed kernels (AHK) were stored at $-80^{\circ} \mathrm{C}$ for further study. 


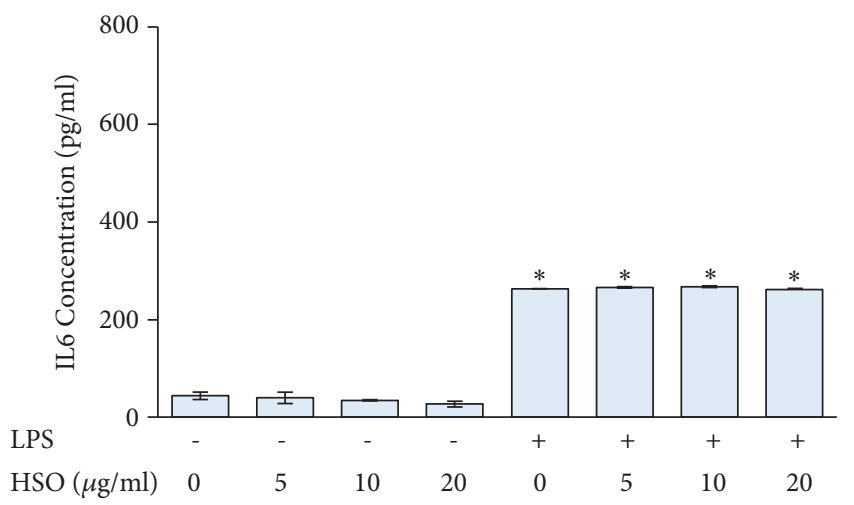

(a)

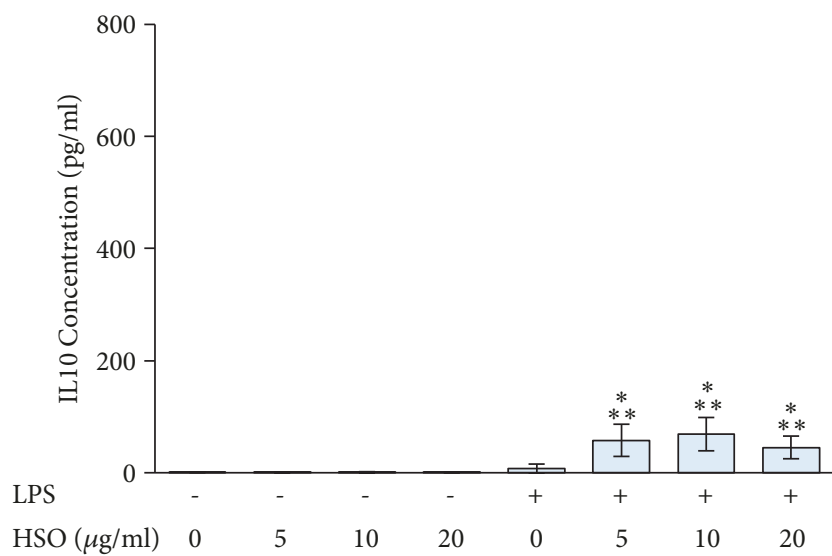

(c)

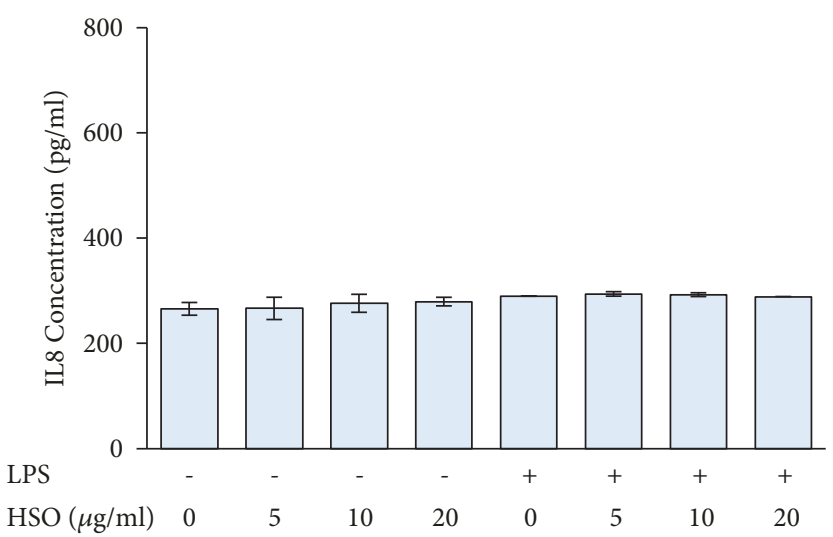

(b)

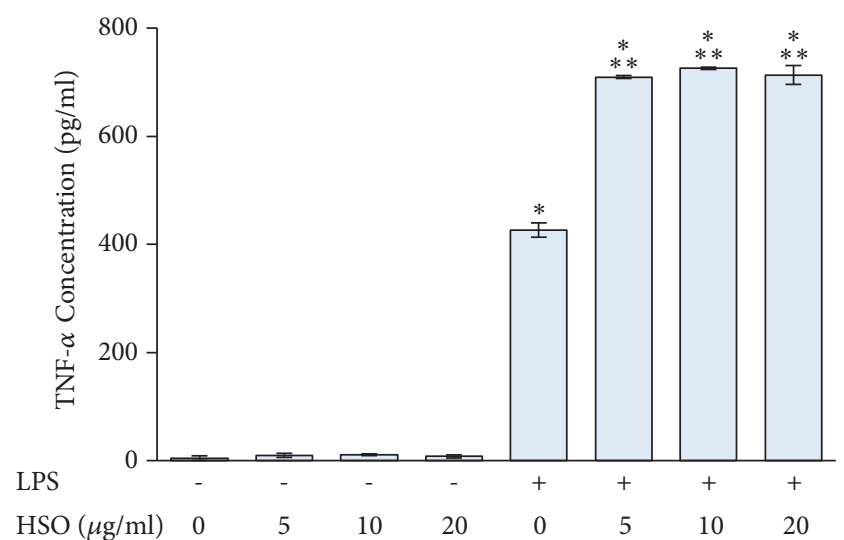

(d)

Figure 2: The effect of HSO on IL6 (a), IL8 (b), IL10 (c), and TNF- $\alpha$ (d) production in PBMCs and LPS-treated PBMCs. PBMCs were separated using Ficoll-Paque density centrifugation, seeded in 12 -well plates, and treated with $10 \mu \mathrm{g} / \mathrm{ml}$ LPS and HSO at the indicated concentration for $24 \mathrm{~h}$. Levels of IL6, IL8, IL10, and TNF- $\alpha$ secretion were determined using ELISA with specific antibodies to each cytokine. $* p<0.05$ compared to control group; $* * p<0.05$ compared to LPS-treated group alone.

H. anthelminthicus hulls were dried at $50^{\circ} \mathrm{C}$ for $30 \mathrm{~min}$, ground into powder, and extracted with $80 \%$ ethanol. Marc from the ethanol extract was then extracted with water by heating on a water bath for $30 \mathrm{~min}$, filtered, and evaporated using a freeze dryer. Ethanol extract of $H$. anthelminthicus seed hulls $(\mathrm{EHH})$ and aqueous extract of $H$. anthelminthicus seed hulls (AHH) were stored at $-80^{\circ} \mathrm{C}$ for further study.

\subsection{Isolation and Culture of Peripheral Blood Mononuclear} Cells. Blood samples were obtained from healthy volunteers at Rajavithi Hospital after approval by the Rajavithi Ethics Committee. Six healthy volunteers (three males and three females) aged 20-40 years with no diseases involved in immune response including acquired immune deficiency syndrome (AIDS), diabetes mellitus, and autoimmune diseases participated in the study. Peripheral blood mononuclear cells (PBMCs) were separated from $25 \mathrm{ml}$ blood using FicollPaque density centrifugation (Pharmacia, Piscataway, NJ, USA). PBMCs were washed with phosphate-buffered saline (PBS) and then cultured in Ham's F12 (Gibco, Grand Island, NY, USA) treated with $10 \%$ heat-inactivated fetal calf serum (Gibco), $100 \mathrm{U} / \mathrm{ml}$ penicillin, and $100 \mu \mathrm{g} / \mathrm{ml}$ streptomycin (Gibco) at $37^{\circ} \mathrm{C}$ in a $5 \% \mathrm{CO}_{2}$ humidified atmosphere.
2.3. The Effect of H. Anthelminthicus Seed Oil and Extracts on PBMC Proliferation. PBMCs were seeded in 96-well tissue culture plates at a density of 10,000 cells per well in Ham's $\mathrm{F} 12$ at $37^{\circ} \mathrm{C}$ in a $5 \% \mathrm{CO}_{2}$ humidified atmosphere for 24 hours. Lipopolysaccharide (LPS; $10 \mu \mathrm{g} / \mathrm{ml}$ ) was added to PBMC culture with $\mathrm{HSO}$ at concentrations of $0,5,10$, and $20 \mu \mathrm{l} / \mathrm{ml}$ or $\mathrm{H}$. anthelminthicus extracts (EHH, EHK, $\mathrm{AHH}$, or AHK) at concentrations of $0,5,10$, and $20 \mu \mathrm{g} / \mathrm{ml}$. The cells were subsequently incubated for 24 hours before applying WST1 cell proliferation assay reagent (Roche Diagnostics, Laval, Quebec) according to the manufacturer's instructions. The percentage of cell proliferation was calculated relative to control PBMCs. The proliferation of control PBMCs at 24 hours was indicated as $100 \%$.

\subsection{The Effect of H. Anthelminthicus Seed Oil and Extracts} on Proinflammatory Cytokine Secretion. PBMCs $\left(5 \times 10^{5}\right.$ cells $/ \mathrm{ml}$ ) in 12-well tissue culture plates were cultured in Ham's $\mathrm{F} 12$ at $37^{\circ} \mathrm{C}$ in a $5 \% \mathrm{CO}_{2}$ humidified atmosphere for 24 hours. Lipopolysaccharide (LPS; $10 \mu \mathrm{g} / \mathrm{ml}$ ) was added to the PBMC culture with $\mathrm{HSO}$ at concentrations of $0,5,10$, and $20 \mu \mathrm{l} / \mathrm{ml}$ or $H$. anthelminthicus extracts (EHH, EHK, AHH, and AHK) at concentrations of $0,5,10$, and $20 \mu \mathrm{g} / \mathrm{ml}$. PBMCs 


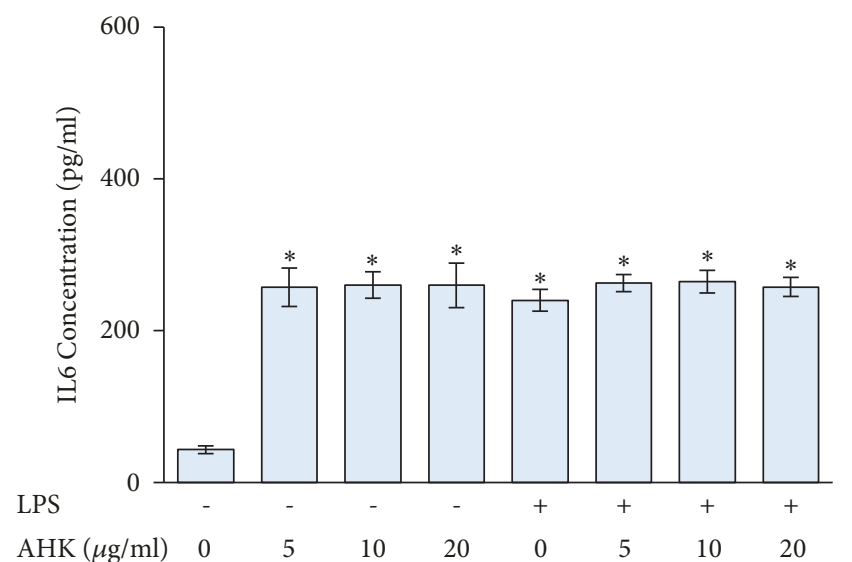

(a)

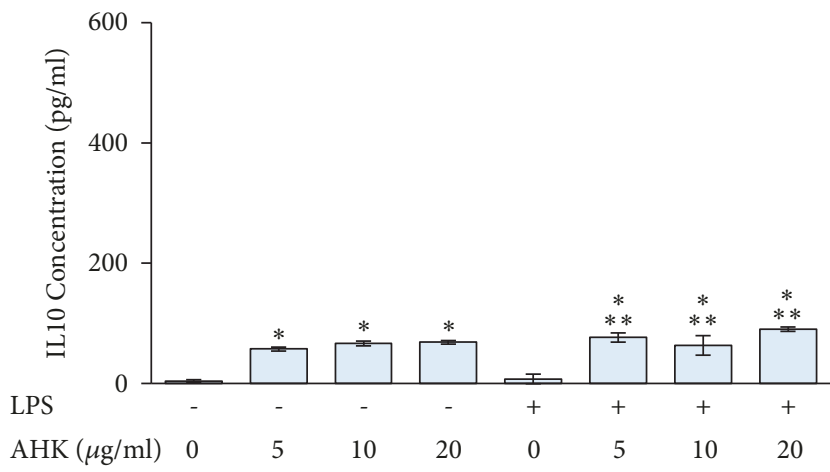

(c)

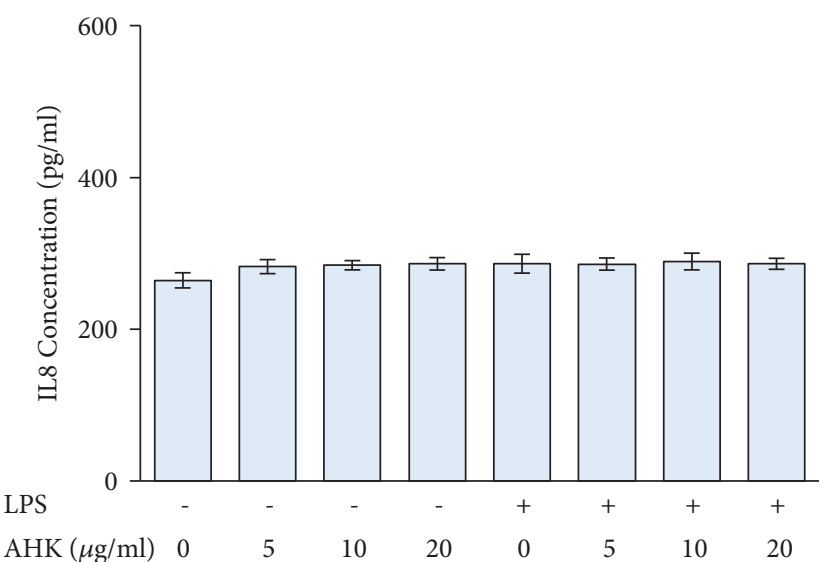

(b)

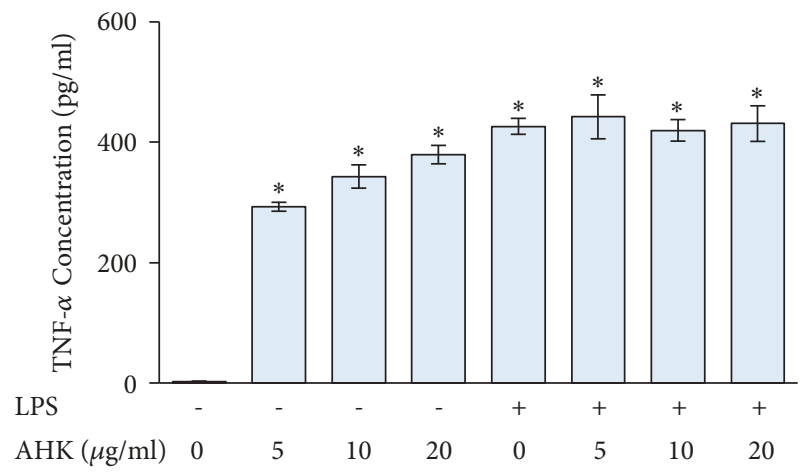

(d)

FIGURE 3: The effect of AHK on IL6 (a), IL8 (b), IL10 (c), and TNF- $\alpha$ (d) production in PBMCs and LPS-treated PBMCs. PBMCs were separated using Ficoll-Paque density centrifugation, seeded in 12-well plates, and treated with $10 \mu \mathrm{g} / \mathrm{ml}$ LPS and AHK at the indicated concentrations for $24 \mathrm{~h}$. The levels of IL6, IL8, IL10, and TNF- $\alpha$ secretion were determined using ELISA with specific antibodies to each cytokine. $* p<0.05$ compared to control group; $* * p<0.05$ compared to LPS-treated group alone.

were subsequently incubated for 24 hours. The supernatant was collected for quantitative analysis of proinflammatory cytokines (IL6, IL8, IL10, and TNF- $\alpha$ ) using an enzymelinked immunosorbent assay kit with a specific antibody to each cytokine (Quantikine ${ }^{\circledR}$ Colorimetric Sandwich ELISA, R\&D Systems, Minneapolis, MN) according to the manufacturer's instructions. Briefly, supernatants from control and treated samples were added to each well of a 96-well plate and incubated for 2 hours at room temperature. After washing, human IL6 (IL8, IL10, or TNF- $\alpha$ ) conjugate (horseradish peroxidase) was added and incubated for 2 hours at room temperature. Then, the samples were washed and incubated with substrate solution [stabilized hydrogen peroxide and stabilized chromogen (tetramethylbenzidine)] for $20 \mathrm{~min}$ at room temperature and protected from light. A $50 \mu \mathrm{l}$ stop solution ( $2 \mathrm{~N}$ sulfuric acid) was added to each well. The color in the wells changed from blue to yellow. The optical density of each well was determined within 30 minutes, using a microplate reader set to $450 \mathrm{~nm}$.

2.5. Statistical Analysis. The experiments were performed in triplicate, and quantitative data were described as the mean \pm standard deviation. Data between three or more groups were compared using one-way analysis of variance (ANOVA) followed by Dunnett's post hoc test. A $p$ value of less than 0.05 was considered to indicate a statistically significant result.

\section{Results}

3.1. The Effect of H. Anthelminthicus Seed Oil and Extract on PBMC Proliferation. PBMCs and LPS-treated PBMCs were cultured with 5-20 $\mu \mathrm{g} / \mathrm{ml} \mathrm{HSO}, \mathrm{AHK}, \mathrm{EHK}, \mathrm{AHH}$, or EHH. The results demonstrated that LPS and all extracts of $H$. anthelminthicus seeds had no effect on PBMC proliferation (Figure 1).

\subsection{The Effect of H. Anthelminthicus Seed Oil and Extracts on Proinflammatory Cytokine Secretion}

3.2.1. The Effect of HSO on Cytokine Secretion. PBMCs were cultured with $5-20 \mu \mathrm{g} / \mathrm{ml} \mathrm{HSO}$ alone or $5-20 \mu \mathrm{g} / \mathrm{ml} \mathrm{HSO}$ with $10 \mu \mathrm{g} / \mathrm{mg}$ LPS. The results demonstrated that LPS induced IL6 and TNF- $\alpha$ secretion of PBMCs but had no effect on IL8 and IL10 secretion. HSO significantly induced TNF- $\alpha$ and IL10 secretion in LPS-treated PBMCs at concentrations 


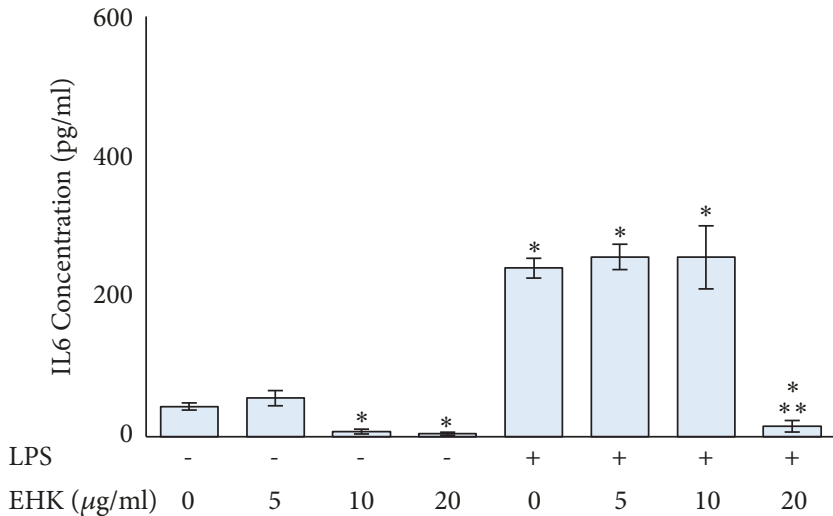

(a)

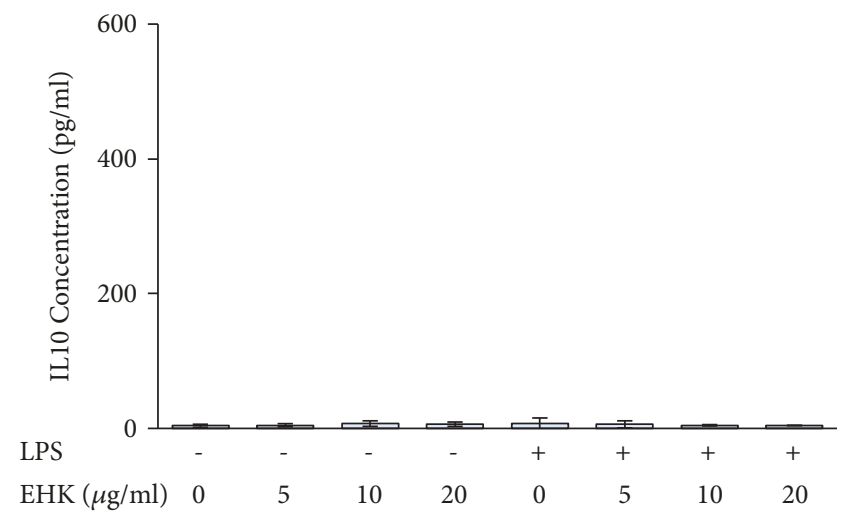

(c)

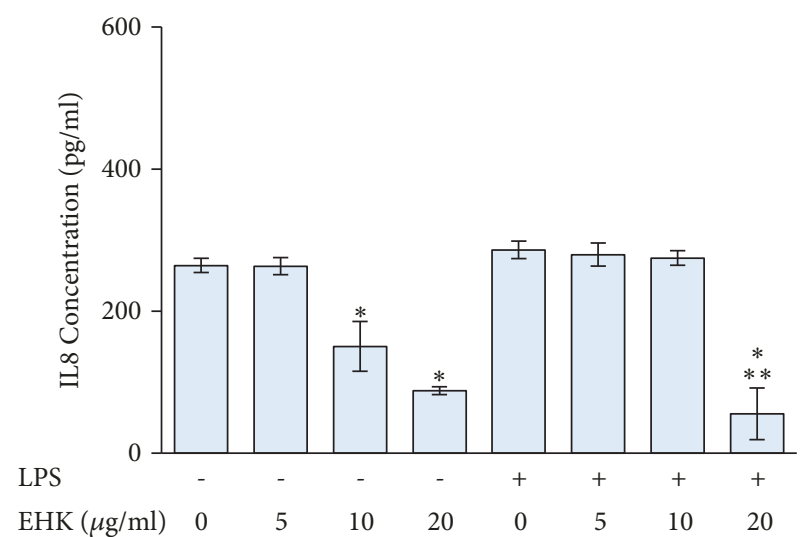

(b)

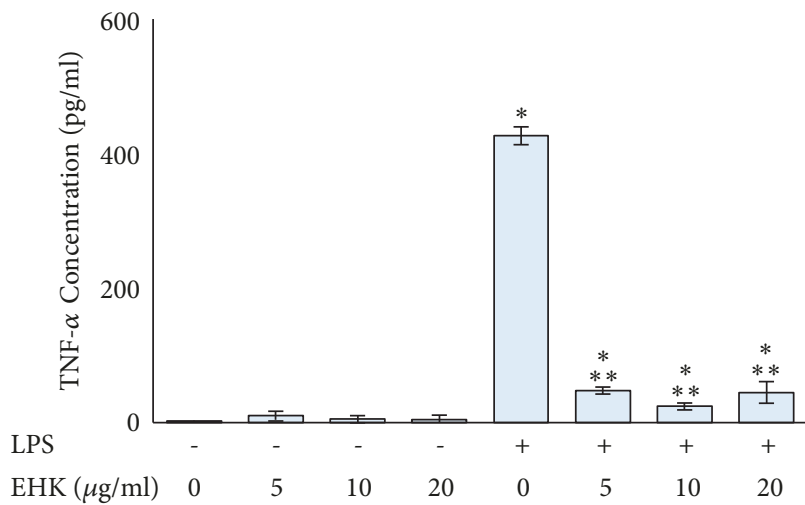

(d)

FIGURE 4: The effect of EHK on IL6 (a), IL8 (b), IL10 (c), and TNF- $\alpha$ (d) production in PBMCs and LPS-treated PBMCs. PBMCs were separated using Ficoll-Paque density centrifugation, seeded in 12 -well plates, and treated with $10 \mu \mathrm{g} / \mathrm{ml}$ LPS and EHK at the indicated concentrations for $24 \mathrm{~h}$. The levels of IL6, IL8, IL10, and TNF- $\alpha$ secretion were determined using ELISA with specific antibodies to each cytokine. $* p<0.05$ compared to control group; $* * p<0.05$ compared to LPS-treated group alone.

of $5-20 \mu \mathrm{g} / \mathrm{ml}$. However, HSO had no effect on the secretion of IL6 and IL8 in PBMCs and LPS-treated PBMCs (Figure 2).

3.2.2. The Effect of AHK on Cytokine Secretion. LPS-treated PBMCs showed significantly increased IL6 and TNF- $\alpha$ secretion, although the secretion of IL8 and IL10 was not different. Treatment with AHK significantly induced IL6, IL10, and TNF- $\alpha$ secretion in PBMCs. AHK and LPS treatment significantly induced IL10 secretion but had no effect on IL6, IL8, and TNF- $\alpha$ secretion (Figure 3).

3.2.3. The Effect of EHK on Cytokine Secretion. LPS treatment alone significantly induced IL6 and TNF- $\alpha$ secretion, while the secretion of IL8 and IL10 was not different from control PBMCs. Treatment with EHK significantly decreased the secretion of IL6 and IL8 at concentrations of 10 and 20 $\mu \mathrm{g} / \mathrm{ml}$. However, EHK had no effect on IL10 and TNF- $\alpha$ secretion. EHK and LPS treatment significantly decreased the secretion of IL6 and IL8 at a concentration of $20 \mu \mathrm{g} / \mathrm{ml}$ and the secretion of TNF- $\alpha$ at a concentration of 5-20 $\mu \mathrm{g} / \mathrm{ml}$. However, EHK had no effect on IL10 secretion in PBMCs and LPS-treated PBMCs (Figure 4).
3.2.4. The Effect of AHH on Cytokine Secretion. Treatment with LPS significantly induced the levels of IL6 and TNF$\alpha$ in PBMCs, whereas IL8 and IL10 levels were not altered. AHH treatment significantly increased IL6, IL10, and TNF$\alpha$ secretion in PBMCs but had no effect on IL8 secretion. Additionally, treatment with AHH and LPS significantly induced IL10 and TNF- $\alpha$ secretion of PBMCs but had no effect on IL6 and IL8 (Figure 5).

3.2.5. The Effect of EHH on Cytokine Secretion. LPS treatment alone significantly released IL6 and TNF- $\alpha$ in PBMCs. However, LPS had no influence on IL8 and IL10 secretion. EHH treatment significantly decreased the secretion of IL6 and IL8 at concentrations of 5,10, and $20 \mu \mathrm{g} / \mathrm{ml}$ in PBMCs. However, EHH had no effect on IL10 and TNF- $\alpha$ secretion. In LPStreated PBMCs, EHH significantly decreased the secretion of IL6, IL8, and TNF- $\alpha$ at concentrations of 5, 10, and $20 \mu \mathrm{g} / \mathrm{ml}$. However, EHH did not influence the level of IL10 in LPStreated PBMCs (Figure 6).

\section{Discussion}

The pathogenesis and clinical manifestation of leprosy are determined by the polarization of the immune response 


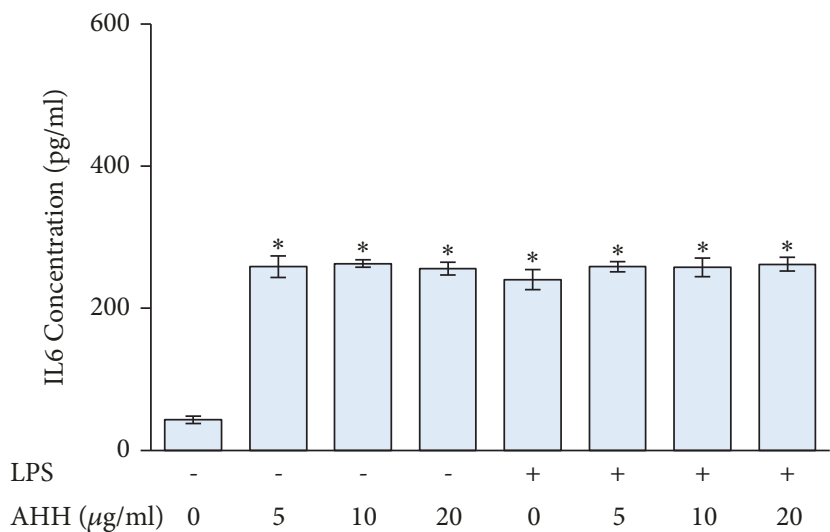

(a)

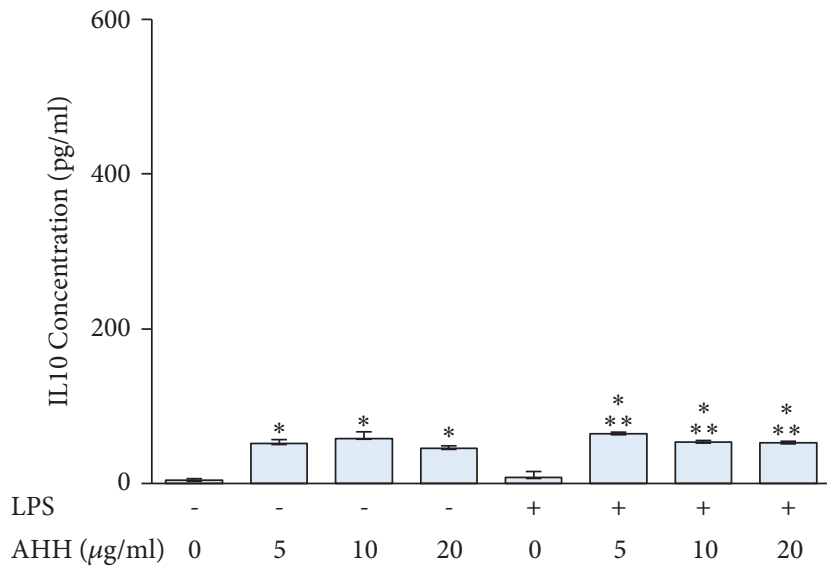

(c)

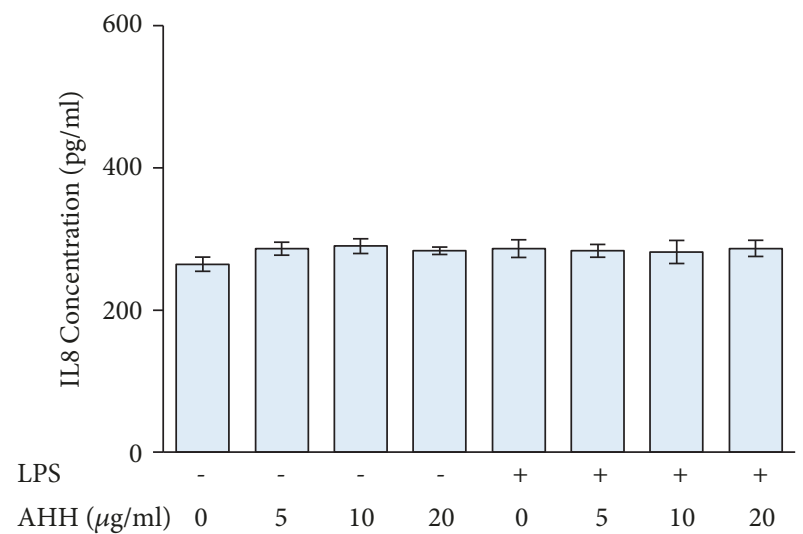

(b)

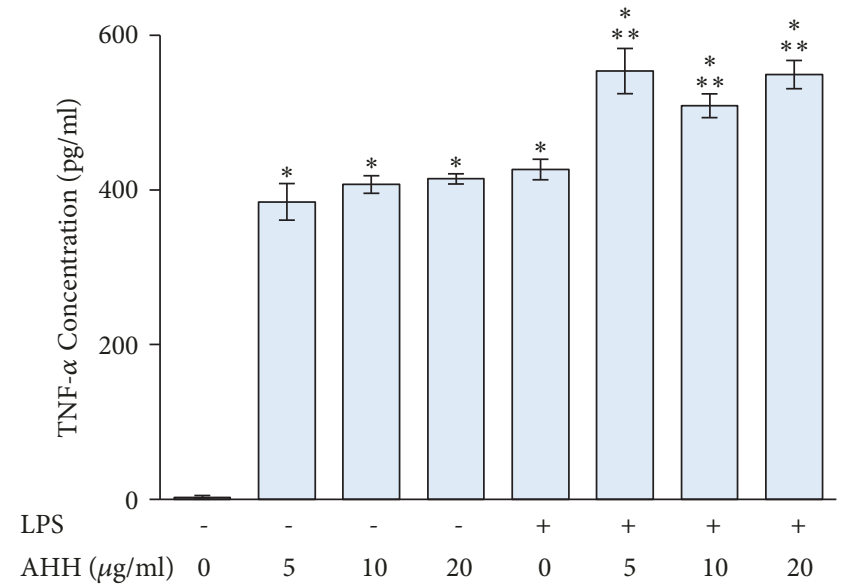

(d)

FIgUrE 5: The effect of AHH on IL6 (a), IL8 (b), IL10 (c), and TNF- $\alpha$ (d) production in PBMCs and LPS-treated PBMCs. PBMCs were separated using Ficoll-Paque density centrifugation, seeded in 12-well plates, and treated with $10 \mu \mathrm{g} / \mathrm{ml} \mathrm{LPS}$ and AHH at the indicated concentrations for $24 \mathrm{~h}$. The levels of IL6, IL8, IL10, and TNF- $\alpha$ secretion were determined using ELISA with specific antibodies to each cytokine. $* p<0.05$ compared to control group; $* * p<0.05$ compared to LPS-treated group alone.

specific to M. leprae [9]. Consequently, the effect of drugs on cytokine secretion associated with the immunological response should play an essential role in leprosy treatment.

Presently, the components of $H$. anthelminthicus seed oil have not been reported. However, the composition of certain chaulmoogra oil has been studied. Chaulmoogra oil from H. kurzii is composed of triglycerides [70-80\% glycerides of cyclopentenyl fatty acid (hydnocarpic, chaulmoogric, and gorlic acids)] and palmitic, stearic, and oleic acids [10]. Chaulmoogra oil from $H$. wightiana is composed of triglycerides (80-90\% glycerides of cyclopentenyl fatty acid) and palmitic, oleic, and steric acids [10]. Chaulmoogra oil from $H$. wightiana contains $48 \%$ hydnocarpic acid, $27 \%$ chaulmoogric acid, gorlic acid, and other acids [11]. Three flavonolignans (hydnowightin, hydnocarpin, and neohydnocarpin) isolated from $H$. wightiana seeds established potent hypolipidemic activity in mice [12]. A new phenolic glycoside isolated from the bark of $H$. annamensis exhibited COX-2 inhibitory activity in vitro [13]. Hydnocarpin and isohydnocarpin from the seed hulls of $H$. wightiana exhibited free radical scavenging, $\alpha$-glucosidase, and moderate $\mathrm{N}$-acetyl $-\beta$-D glucosaminidase inhibitory activities, which may be responsible for antidiabetic properties [14].

In this study, LPS induced proinflammatory cytokine (IL6 and TNF- $\alpha$ ) secretion of PBMCs but had no effect on chemoattractant cytokine IL8 and anti-inflammatory cytokine IL10. HSO had no effect on the proliferation and cytokine secretion of PBMCs. However, HSO showed synergism with LPS on TNF- $\alpha$ secretion of PBMCs. Consequently, the use of HSO might be imprudent for patients infected with Gram-negative bacteria due to the induction of proinflammatory cytokines.

Our study demonstrated that EHH and EHK inhibit the release of inflammatory cytokines from PBMCs and LPStreated PBMCs. A previous study demonstrated that hydnocarpin, the main product among flavonolignans, showed good anti-inflammatory and antineoplastic activity in vivo [12]. The major cyclopentenyl fatty acids, including gorlic acid, chaulmoogric acid, and hydnocarpic acid, from seeds of Carpotroche brasiliensis demonstrated significant oral antiinflammatory and peripheral antinociceptive effects in vivo [15]. Furthermore, silybin, the major flavonolignan from 


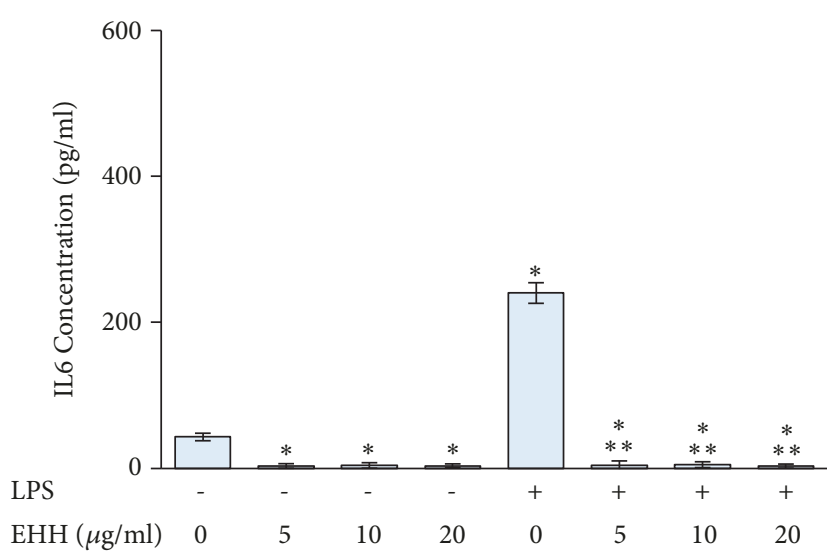

(a)

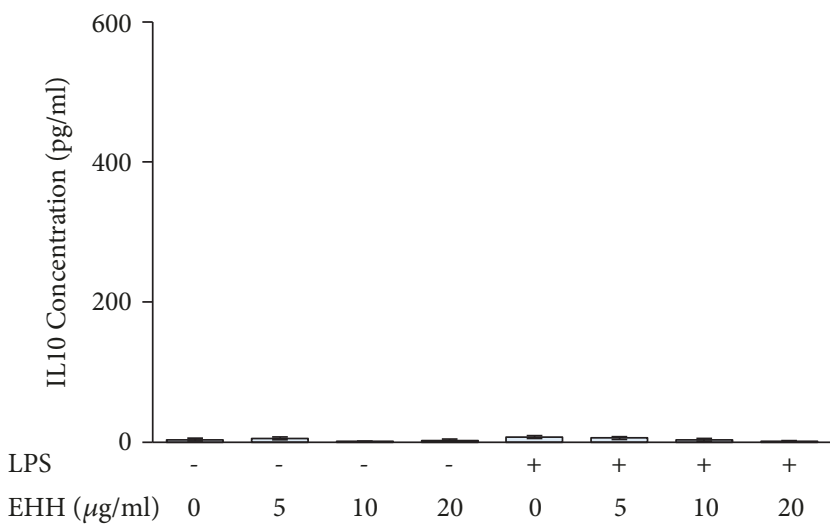

(c)

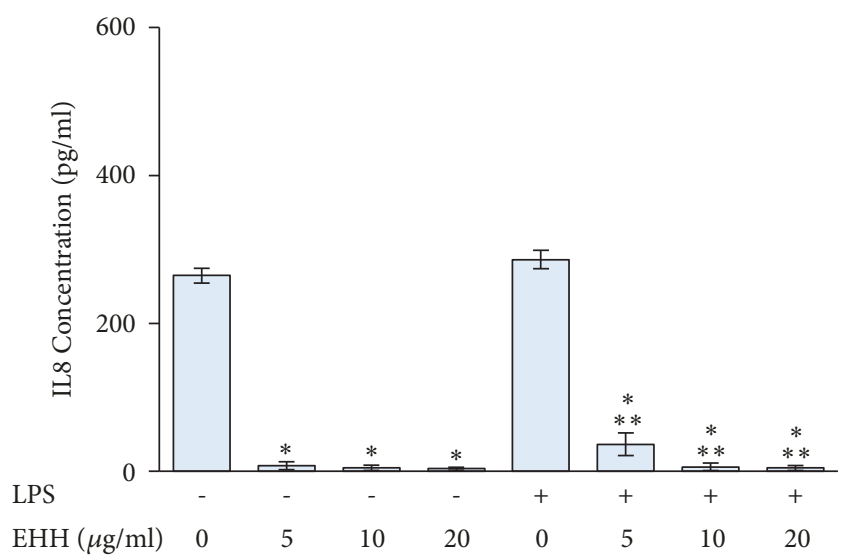

(b)

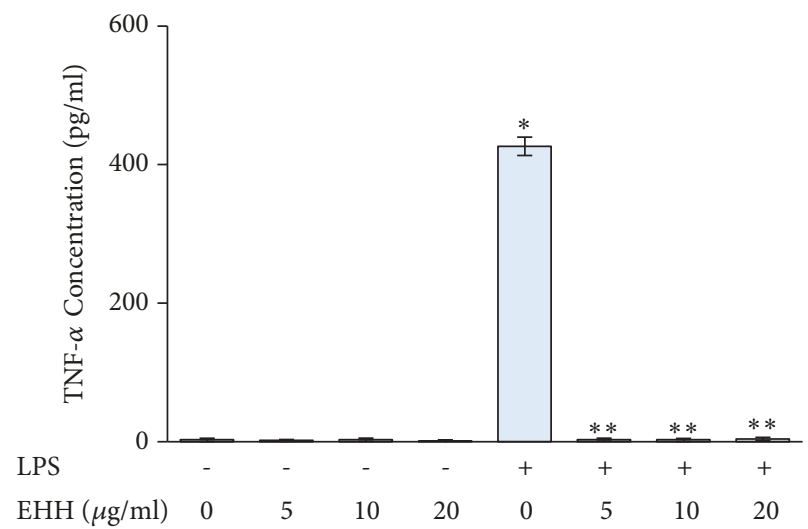

(d)

FIGURE 6: The effect of EHH on IL6 (a), IL8 (b), IL10 (c), and TNF- $\alpha$ (d) production in PBMCs and LPS-treated PBMCs. PBMCs were separated using Ficoll-Paque density centrifugation, seeded in 12-well plates, and treated with $10 \mu \mathrm{g} / \mathrm{ml} \mathrm{LPS}$ and EHH at the indicated concentration for $24 \mathrm{~h}$. The levels of IL6, IL8, IL10, and TNF- $\alpha$ secretion were determined using ELISA with specific antibodies to each cytokine. $* p<0.05$ compared to control group; $* * p<0.05$ compared to LPS-treated group alone.

Silybum marianum seed extracts, demonstrated an inhibitory effect on LPS-induced production of TNF- $\alpha$ and IL- $1 \beta$ and activation of NF- $\kappa$ B and the NLRP 3 inflammasome in mice [16]. It is suggested that EHH and EHK might contain flavonolignan-like compounds that inhibit the proinflammatory cytokine secretion of PBMCs. Flavonolignan is soluble in organic solvent. The aqueous extract of $H$. anthelminthicus seed should not contain flavonolignan. However, AHH and AHK induce proinflammatory cytokine (IL6 and TNF- $\alpha$ ) production in PBMCs similar to LPS stimulation. It is implicit that $\mathrm{AHH}$ and $\mathrm{AHK}$ might induce inflammation. Consequently, the usage of $H$. anthelminthicus seed extract should be consciously considered.

This is the first study of $H$. anthelminthicus for the immune response. Our study explored the effect of $H$. anthelminthicus seed kernel and hull extracts on proinflammatory cytokine (IL6, IL8, and TNF- $\alpha$ ) production. However, the chemical constituents of $H$. anthelminthicus seed hulls and kernels are unknown. Fractions of $H$. anthelminthicus demonstrated various effects. Consequently, the solvent and extraction process should be verified for the therapeutic application of $H$. anthelminthicus.
$\mathrm{AHH}$ and AHK induced proinflammatory cytokine. We suggested that AHH and AHK will be a great benefit for patients with lepromatous leprosy who have a poor cellular immune response against $M$. leprae. Meanwhile, the ethanol extracts of $H$. anthelminthicus seed hulls and kernels demonstrated an inhibitory effect on proinflammatory cytokine secretion. They might influence the downregulation of innate immune and cell-mediated immune responses due to the inhibition of IL6, IL8, and TNF. These extracts should be used depending on the immune response of the host, which determines the manifestation of the disease. Consequently, the inhibitory effect on proinflammatory cytokines should be considered as anti-inflammatory agents for the treatment of inflammatory diseases, including systematic inflammatory response syndrome (SIRS), severe sepsis, cancers, and autoimmune diseases.

Further studies should be performed to elucidate the chemical constituents of $H$. anthelminthicus seed hulls and kernels. Because of the study design limitations, this research was conducted with PBMCs from healthy volunteers. Consequently, further study should be performed using PBMCs from leprosy patients or PBMCs treated with M. leprae 
antigen to study the effect of $H$. anthelminthicus on cytokines secretion. Moreover, an in vivo study is important to investigate the potential application of $H$. anthelminthicus for the clinical treatment of inflammation in a variety of diseases caused by a severe immune response.

\section{Data Availability}

The data used to support the findings of this study are available from the corresponding author upon request.

\section{Conflicts of Interest}

The authors declare that there are no conflicts of interest.

\section{Acknowledgments}

This study was funded by the National Research Council of Thailand (no. 2553-123). The manuscript underwent English language editing by editors at American Journal Experts.

\section{References}

[1] M. R. Sahoo, S. P. Dhanabal, A. N. Jadhav et al., "Hydnocarpus: An ethnopharmacological, phytochemical and pharmacological review," Journal of Ethnopharmacology, vol. 154, no. 1, pp. 17-25, 2014.

[2] K. K. Mohanty, B. Joshi, K. Katoch, and U. Sengupta, "Leprosy reactions: humoral and cellular immune responses to M. leprae, 65kDa, 28kDa, and $18 \mathrm{kDa}$ antigens," vol. 72, pp. 149-158, 2004.

[3] D. S. Ridley and W. H. Jopling, "Classification of leprosy according to immunity. A five-group system," International Journal of Leprosy and Other Mycobacterial Diseases, vol. 34, no. 3, pp. 255-273, 1966.

[4] A. Polycarpou, S. L. Walker, and D. N. Lockwood, "A Systematic Review of Immunological Studies of Erythema Nodosum Leprosum," Frontiers in Immunology, vol. 8, 2017.

[5] J. L. Turk and M. F. Waters, "Cell-mediated immunity in patients with leprosy.”, The Lancet, vol. 2, no. 7614, pp. 243-246, 1969.

[6] C. J. Moran, J. L. Turk, G. Ryder, and M. F. R. Waters, "Evidence for circulating immune complexes in lepromatous leprosy," The Lancet, vol. 300, no. 7777, pp. 572-573, 1972.

[7] R. M. Bhat and C. Prakash, "Leprosy: an overview of pathophysiology," Interdisciplinary Perspectives on Infectious Diseases, vol. 2012, Article ID 181089, 6 pages, 2012.

[8] S. Józefowski, A. Sobota, A. Pawłowski, and K. Kwiatkowska, "Mycobacterium tuberculosis lipoarabinomannan enhances LPS-induced TNF- $\alpha$ production and inhibits NO secretion by engaging scavenger receptors," Microbial Pathogenesis, vol. 50, no. 6 , pp. $350-359,2011$.

[9] A. B. D. L. Fonseca, M. D. V. Simon, R. A. Cazzaniga et al., “The influence of innate and adaptative immune responses on the differential clinical outcomes of leprosy," Infectious Diseases of Poverty, vol. 6, no. 1, article no. 5, 2017.

[10] R. N. Chopra, Indigenous Drugs of India, Dhur \& Sons Private Ltd., Calcutta, India, 2nd edition, 1958.

[11] W. C. Evans, Trease and Evans Pharmacognosy, Bailliere Tindall, London, UK, 1992.

[12] D. K. Sharma, "Hypolidpidemic, anti-inflammatory, and antineoplastic activity and cytotoxicity of flavonolignans isolated from Hydnocarpus wightiana seeds," Journal of Natural Products, vol. 54, no. 5, pp. 1298-1302, 1991.

[13] H.-M. Shi, J. Wen, C.-Q. Jia et al., "Two new phenolic glycosides from the barks of Hydnocarpus annamensis and their antiinflammatory and anti-oxidation activities," Planta Medica, vol. 72, no. 10, pp. 948-950, 2006.

[14] S. V. Reddy, A. K. Tiwari, U. S. Kumar, R. J. Rao, and J. M. Rao, "Free radical scavenging, enzyme inhibitory constituents from antidiabetic ayurvedic medicinal plant Hydnocarpus wightiana blume," Phytotherapy Research, vol. 19, no. 4, pp. 277-281, 2005.

[15] J. A. Lima, A. S. Oliveira, A. L. P. de Miranda, C. M. Rezende, and A. C. Pinto, "Anti-inflammatory and antinociceptive activities of an acid fraction of the seeds of Carpotroche brasiliensis (Raddi) (Flacourtiaceae)," Brazilian Journal of Medical and Biological Research, vol. 38, no. 7, pp. 1095-1103, 2005.

[16] B. Zhang, B. Wang, S. Cao, Y. Wang, and D. Wu, "Silybin attenuates LPS-induced lung injury in mice by inhibiting NF$\kappa \mathrm{B}$ signaling and NLRP3 activation," International Journal of Molecular Medicine, vol. 39, no. 5, pp. 1111-1118, 2017. 


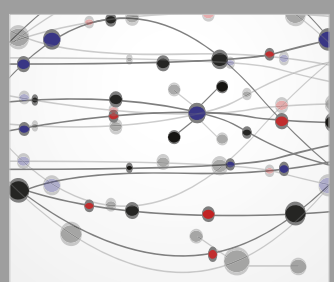

The Scientific World Journal
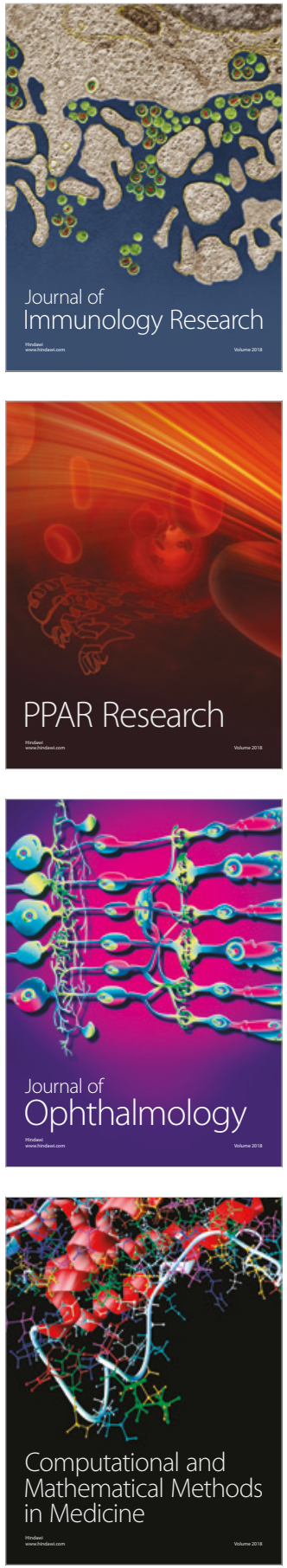

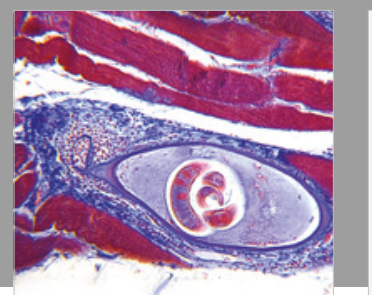

Gastroenterology Research and Practice

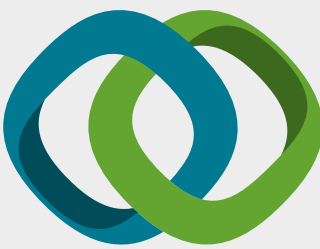

\section{Hindawi}

Submit your manuscripts at

www.hindawi.com
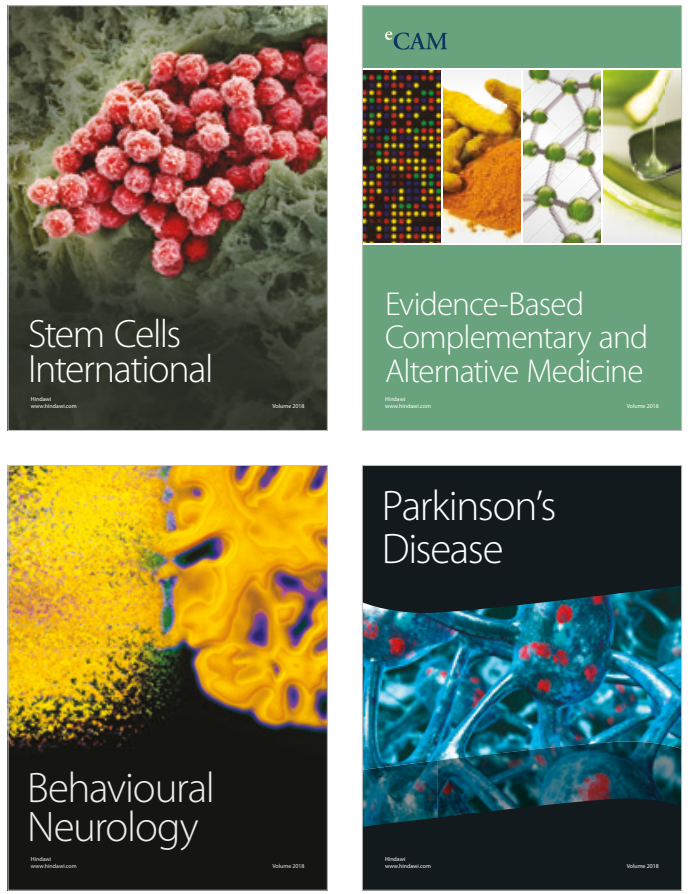

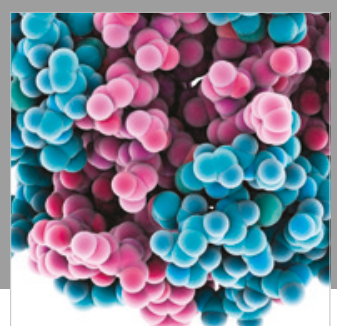

ournal of

Diabetes Research

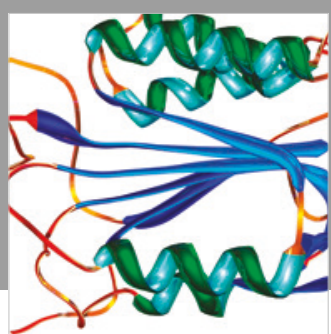

Disease Markers
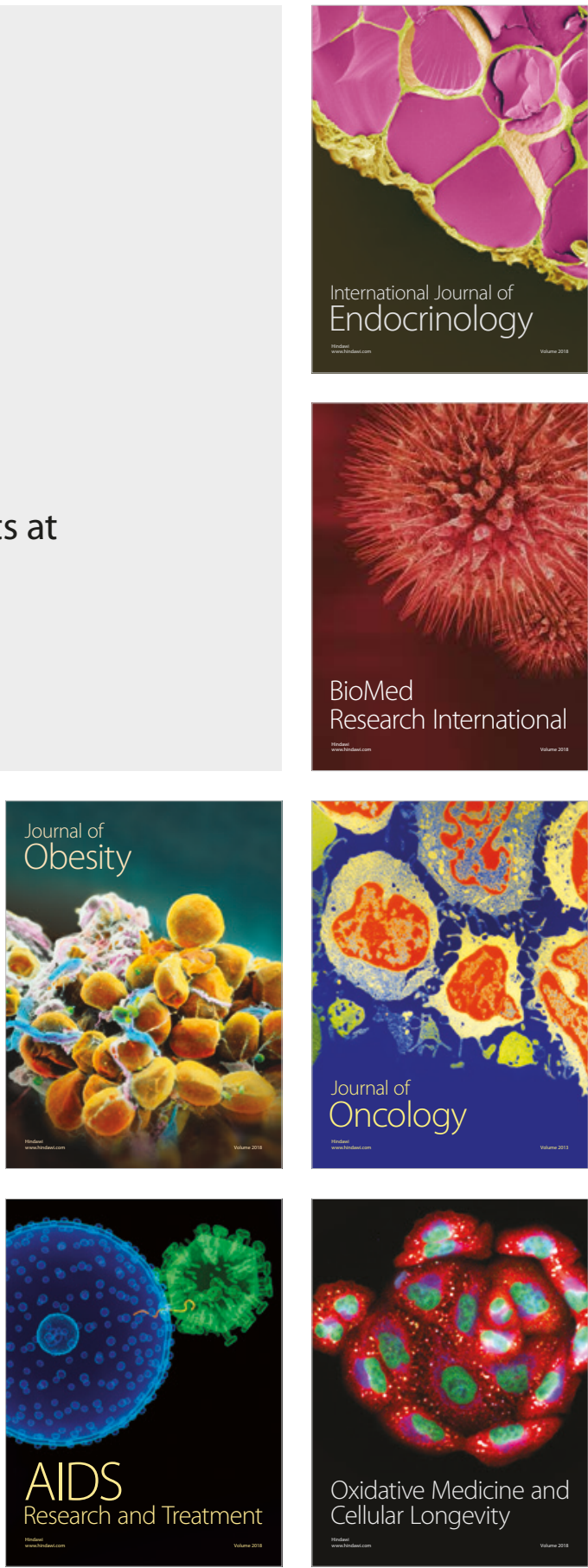